\title{
Production du phytoplancton et du bactérioplancton dans le lac de retenue de Pareloup
}

\section{Production of phytoplankton and bacterioplankton in Pareloup reservoir}

\author{
J. Capblancq, P. Lavandier et M. Petit
}

Laboratoire d'Hydrobiologie, URA 695 C.N.R.S., Université Paul Sabatier, 118 route de Narbonne, F-31062 Toulouse Cedex, France.

\begin{abstract}
Résumé. - La biomasse et la production du phytoplancton ont été étudiées parallèlement à la biomasse et à la production du bactérioplancton hétérotrophe dans le réservoir de Pareloup. Les productions phytoplanctoniques et bactériennes ont été respectivement mesurées à partir des taux d'incorporation de ${ }^{14} \mathrm{C}$ bicarbonate et de ${ }^{3} \mathrm{H}$ thymidine.

Au cours de l'année, la moyenne des concentrations en chlorophylle a dans la zone euphotique varie de $2 \mathrm{mg} \cdot \mathrm{m}^{-3}$ (juin-août) à $20 \mathrm{mg} \cdot \mathrm{m}^{-3}$ (printemps). La production brute moyenne annuelle du phytoplancton est d'environ $80-85 \mathrm{~g} \mathrm{C.} \mathrm{m}^{2}$, valeur typique des lacs oligo-mésotrophes. La transparence de l'eau et les paramètres de la relation photosynthèse-lumière $\left(\mathrm{P}^{\mathrm{B}} \max , \alpha^{\mathrm{B}}\right)$ sont inversement corrélés à la biomasse du phytoplancton de sorte que les effets antagonistes des variations de biomasse et d'irradiance journalière se compensent en partie. La comparaison des taux d'assimilation du $\mathrm{C}$ et des taux de variation de biomasse phytoplanctonique indique un couplage étroit entre les processus de fixation et de perle de carbone. Au cours d'un cycle nycthéméral, les pertes moyennes par respiration représenteraient de $33 \%$ à $82 \%$ du C incorporé selon les rapports $R^{B} / P^{B}$ max appliqués $(0,03$ à 0,1 pour les diatomées; 0,07 à 0,15 pour le phytoplancton estival).

Sur toute la colonne d'eau, la densité des bactéries planctoniques varie de $2,3.10^{9}$ à

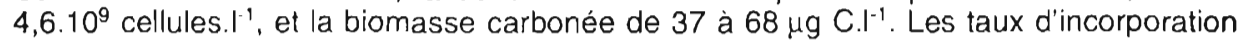
de thymidine tritiée dans le précipité TCA froid varient de 0,8 à 17,2 picomoles. $\left.\right|^{-1} \cdot h^{-1}$; ils correspondent à une production bactérienne nette inférieure à $0,2 \mu \mathrm{g} \mathrm{C} . \mathrm{l}^{-1} \mathrm{j}^{-1}$ en hiver et supérieure à $4,5 \mu \mathrm{g} \mathrm{C} . .^{-1} . j^{-1}$ en été; environ $55 \%$ de la production a lieu dans la zone euphotique. La production bactérienne brute représente $7 \%$ de la production photosynthétique brute au printemps et plus de $70 \%$ à la fin de l'été. Au cours d'un cycle annuel et en considérant l'ensemble du lac, le carbone nécessaire à la production bactérienne représente environ $1 / 3$ de la production brute autotrophe.
\end{abstract}

Mot-clés. - Phytoplancton, production primaire, bactérioplancton, production secondaire. 
Abstract. - Biomass and primary production of phytoplankton were compared with biomass and production of heterotrophic bacterioplankton in the reservoir of Pareloup. Phytoplankton and bacterioplankton productions were estimated from ${ }^{14} \mathrm{C}$ bicarbonate and ${ }^{3} \mathrm{H}$ thymidine incorporation rates respectively.

Over the year, mean euphotic zone concentrations of chlorophyll a ranged from $2 \mathrm{mg} \cdot \mathrm{m}^{-3}$ (june-august) to $20 \mathrm{mg} \cdot \mathrm{m}^{-3}$ (spring diatom bloom). Gross annual phytoplankton production was about $80-85 \mathrm{~g} \mathrm{C} . \mathrm{m}^{-2}$, a value typical for slightly meso-eutrophic lakes. Water transparency and parameters of the photosynthesis-irradiance relationship $\left(\mathrm{P}^{\mathrm{B}} \max , \sigma^{\mathrm{B}}\right)$ were inversely correlated with phytoplankton biomass; accordingly, the effects of seasonal variations of biomass and mean daily radiance fluxes on integral photosynthesis can to a significant extent be compensated for. Comparison of carbon fixation rates and actual rates of changes of phytoplankton biomass indicated a close coupling between carbon fixation and loss processes. Daily respiratory losses represented, on average, $33 \%$ to $82 \%$ of the carbon taken up during the daylight period depending on the assumed

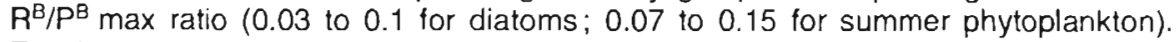

For the water column, integrated estimates of bacterioplankton abundance ranged from $2,3.10^{9}$ to $4,6.10^{9}$ cells. $\mathrm{I}^{-1}$, and carbon biomass from 37 to $68 \mu \mathrm{g} \mathrm{C.} \mathrm{I}^{-1}$; the thymidine incorporation rates ranged from 0.8 to 17,2 picomoles. $\left.\right|^{-1} \cdot h^{-1}$, leading to net bacterial production estimates of less than $0,2 \mu \mathrm{g} \mathrm{C} . l^{-1} . \mathrm{d}^{-1}$ in winter to $4.5 \mu \mathrm{g} \mathrm{C} . \mathrm{l}^{-1} . \mathrm{d}^{-1}$ in summer. About $55 \%$ of the production occured in the euphotic layers. Gross bacterial production represented $7 \%$ of the gross primary production during the phytoplanktonic spring bloom and more than $70 \%$ in late summer.

Over the year, the bacterial carbon requirement was about $1 / 3$ of the gross autotrophic production for the whole lake.

Key words. - Phytoplankton, primary production, bacterioplankton, heterotrophic production.

\section{INTRODUCTION}

L'évolution des propriétés physiques et chimiques de l'eau stockée dans les retenues hydroélectriques est étroitement liée aux processus de production et de dégradation de matière organique au sein du réseau trophique pélagique.

La base de ce fonctionnement est assurée par la production photosynthétique du phytoplancton dont le contrôle par la lumière peut être défini par la combinaison de quatre variables:

- l'intensité du rayonnement lumineux incident, lo;
- le coefficient d'atténuation de la lumière dans l'eau, $\varepsilon_{v}$;

- la biomasse de phytoplancton présente, B;

- les valeurs caractéristiques de la relation photosynthèse-éclairement : capacité photosynthétique en lumière saturante $\left(P^{B} \max \right)$ et rendement photosynthétique en lumière limitante $\left(\alpha^{\mathrm{B}}\right)$.

La biomasse phytoplanctonique produite est transformée au long de la chaine trophique et la matière organique résiduelle est en définitive dégradée par les populations bactériennes planctoniques et benthiques. 
Les corrélations établies entre les biomasses et/ou entre les productions de phytoplancton et de bactérioplancton dans différents milieux pélagiques marins ou lacustres (cf Simon \& Yilzer 1987, Del Giorgio \& Peters 1993, Valiela 1991), indiquent qu'une grande partie des matières organiques produites par le phytoplancton est utilisée par les bactéries hétérotrophes. A partir de ces corrélations, Valiela (op. cit) estime à $40 \%$ en moyenne la part de production primaire nette exploitée par le bactérioplancton dans la couche euphotique des lacs et des océans.

Ce travail rassemble les résultats de biomasses et de productions photosynthétique et bactérienne effectuées dans la zone pélagique du lac de Pareloup entre 1983 et 1988 dans les buts (1) de dégager les principaux facteurs de contrôle de ces processus et (2) d'évaluer le flux de matière organique transférée des producteurs primaires aux bactéries au cours d'un cycle annuel.

\section{MATÉRIEL ET MÉTHODES}

\section{Biomasse de phytoplancton}

Pour estimer le carbone du phytoplancton nous avons utilisé les relations carbone-biovolume établies par Reynolds (1984) et appliquées aux biovolumes d'algues établis à partir d'échantillons fixés par du glutaraldéhyde (Le Cohu et al. 1991).

Les pigments photosynthétiques ont été dosés par une méthode spec- trophotométrique décrite par Marker et al. (1980) en utilisant de l'éthanol à $95 \%$ porté à ébullition pour l'extraction. La D.O. de l'extrait a été mesurée avant et après acidification pour estimer la fraction de phéopigments.

Le carbone (POC) et l'azote (PON) particulaires ont été déterminés sur les matières en suspension retenues par filtration de $10 \mathrm{~cm}^{3}$ d'eau sur filtres en fibre de verre (Whatman, GF/F); les échantillons d'eau ont été préalablement filtrés sur un tamis de $200 \mu \mathrm{m}$ pour éliminer le zooplancton. $\mathrm{La}$ mesure est basée sur une combustion à $900^{\circ} \mathrm{C}$ en présence d'oxyde de cuivre et un dosage par chromatographie gaz du $\mathrm{CO}_{2}$ et du $\mathrm{N}_{2}$ libérés (Dalger 1982). Le phosphore particulaire (Ppart) a été déterminé par différence entre les dosages de Ptotal dans deux sous-échantillons d'eau respectivement filtrés sur tamis de $200 \mu \mathrm{m}$ et sur filtre de $0,45 \mu \mathrm{m}$.

\section{Production de phytoplancton}

Les mesures de production photosynthétique ont été effectuées dans des flacons de verre transparents et opaques d'une capacité de $125 \mathrm{~cm}^{3}$, immergés à différentes profondeurs de la couche euphotique pendant 2 heures autour du midi solaire après ajout de $55 \mathrm{KBq}$ de ${ }^{14} \mathrm{CO}^{3} \mathrm{NaH}$ (CEA, Saclay). Dès la fin de la période d'incubation, $50 \mathrm{~cm}^{3}$ d'échantillon ont été filtrés sur un filtre d'une porosité de $10 \mu \mathrm{m}, 50 \mathrm{~cm}^{3}$ sur un filtre d'une porosité de $0,45 \mu \mathrm{m}$. Après rinçage avec $15 \mathrm{~cm}^{3}$ d'eau du lac préfiltrée, les filtres ont été immédiatement transférés 
dans des fioles contenant $5 \mathrm{~cm}^{3}$ de liquide scintillant (Ready Solv $\mathrm{HP} / \mathrm{b}$, Beckman). La radioactivité des filtres et celle des solutions ont été mesurées par scintillation liquide; les valeurs correspondant aux flacons opaques ont été soustraites de celles des flacons transparents. Les concentrations de ${ }^{12} \mathrm{CO}_{2}$ ont été calculées à partir des mesures de $\mathrm{pH}$ et d'alcalinité.

L'éclairement incident a été calculé à partir des valeurs fournies par un pyranomètre installé près du lac et couplé à un intégrateur en considérant que la fraction comprise entre les longueurs d'onde de 400 et $700 \mathrm{~nm}$ (PAR) est égale à $46 \%$ du rayonnement global et que les pertes par réflexion à la surface du lac sont de $10 \%$.

Nous avons utilisé une sonde immergeable (LI-192 S) reliée à un quantamètre (Lambda Instruments) pour mesurer l'atténuation de la lumière dans l'eau. Le coefficient d'atténuation vertical des PAR $\left(\varepsilon_{v}\right)$ a été calculé par régression des valeurs mesurées par rapport à la profondeur.

\section{Densité et biomasse bacté- riennes}

Les bactéries sont dénombrées par microscopie en épifluorescence après coloration à l'acridine orange (Hobbie et al. 1977) des échantillons fixés par du formol, $2 \%$ en concentration finale. Le volume des cellules est estimé à partir de photographies des cellules colorées et converti en biomasse carbonée par application d'un facteur compris entre 14 et $21 \mathrm{fg} \mathrm{C.cellule}{ }^{-1}$ selon sa taille (Simon et Azam 1989). Sur chaque échantillon, 1000 cellules au moins ont été comptées et 150 mesurées. La différence moyenne entre les duplicats est de $6 \%$.

\section{Production bactérienne}

La production bactérienne a été estimée à partir des taux d'incorporation de [méthyl- $\left.{ }^{3} \mathrm{H}\right]$ thymidine selon la procédure de base de Fuhrman \& Azam (1982) appliquée avec une concentration saturante de $20 \mathrm{nM}$ de ${ }^{3} \mathrm{H}$-thymidine $\left(1,66 \mathrm{Tbq} \cdot \mathrm{mmole}^{-1}\right)$. Quatre ou cinq sous échantillons de $8 \mathrm{~cm}^{3}$, dont deux témoins fixés par du formol à $2 \%$, ont été utilisés à chaque point de mesure et incubés pendant 20 à 40 minutes autour du midi solaire à la température du milieu. L'incorporation de thymidine était stoppée par addition de formol. Afin d'éviter leur oxygénation, les échantillons d'eau profonde ont été prélevés à l'aide d'une pompe péristaltique et injectés par l'intermédiaire d'une aiguille au fond de tubes autoclavés de $12 \mathrm{~cm}^{3}$. Les tubes remplis par débordement de 40 à $50 \mathrm{~cm}^{3}$ d'eau étaient obturés par un bouchon de caoutchouc préalablement percé de deux aiguilles permettant l'injection de thymidine et de formol et l'évacuation de l'excès d'eau.

Les taux d'incorporation de thymidine tritiée sont convertis en taux de production cellulaire en appliquant un facteur de $0,5.10^{9}$ cellules formées par nanomole de thymidine incorporée dans le précipité de TCA froid (Servais \& Lavandier, 1993) 


\section{Présentation des résultats}

Les profils de biomasse et d'activité photosynthétique du phytoplancton obtenus par des mesures réalisées à différentes profondeurs dans la couche euphotique (Capblancq et al., 1988 ) ont été intégrés par planimétrie. Les figures qui représentent le cycle annuel d'évolution de la biomasse et de la production photosynthétique ont été construites en rassemblant les résultats de 58 profils de mesures réalisées entre 1983 et 1989.

La production photosynthétique constituant la principale source de carbone pour les bactéries, nous avons considéré séparément les zones euphotique (ze) et aphotique (za) pour reporter les résultats de mesure de la production bactérienne. A partir des 28 profils réalisés au cours de l'étude (cf. fig. 10), nous avons établi pour chacune des deux zones l'évolution saisonnière moyenne des variables mesurées. Les résultats reportés dans le texte correspondent aux moyennes \pm l'erreur standard. Les moyennes mensuelles des estimations sont utilisées pour comparer les productions autotrophes et hétérotrophes.

\section{RÉSULTATS}

\section{Evolution saisonnière du phytoplancton}

D'une superficie de $12,6 \mathrm{~km}^{2}$ pour une profondeur moyenne à la cote maximale de $12,5 \mathrm{~m}$, le lac de Pareloup a un régime thermique de type monomictique chaud, avec une longue période d'isothermie (début octobre-fin mai) et une phase de stratification thermique qui s'étend de la fin mai à la fin septembre (fig. 1).

Associées à ce régime thermique, les variations saisonnières de la biomasse de phytoplancton se reproduisent chaque année de manière identique (fig. 2). Les poussées de phytoplancton correspondent aux périodes d'isothermie printanière - (la biomasse est alors presque exclusivement formée de Diatomées avec une très forte dominance de Asterionella formosa) - et d'érosion de la thermocline en début d'automne. La formation d'un gradient thermique dans la deuxième quinzaine du mois de mai marque le début d'une phase d'eau claire estivale qui se prolonge pendant toute la période de stratification. Cette évolution cyclique a fait l'objet d'une analyse détaillée par Le Cohu et al. (1991).

La distribution verticale de la biomasse dans la couche euphotique est le plus souvent homogène mais l'augmentation de la transparence peut conduire en été à la formation d'un maximum de chlorophylle au niveau de la thermocline, le plus souvent lié au développement de Gonyostomum semen (Capblancq et al. 1988; Le Cohu et al., 1989; 1991).

Les corrélations (fig. 3) entre les concentrations en chlorophylle-a, la biomasse de phytoplancton (équivalent en carbone du biovolume) et la composition du seston en carbone organique (COP), azote organique 

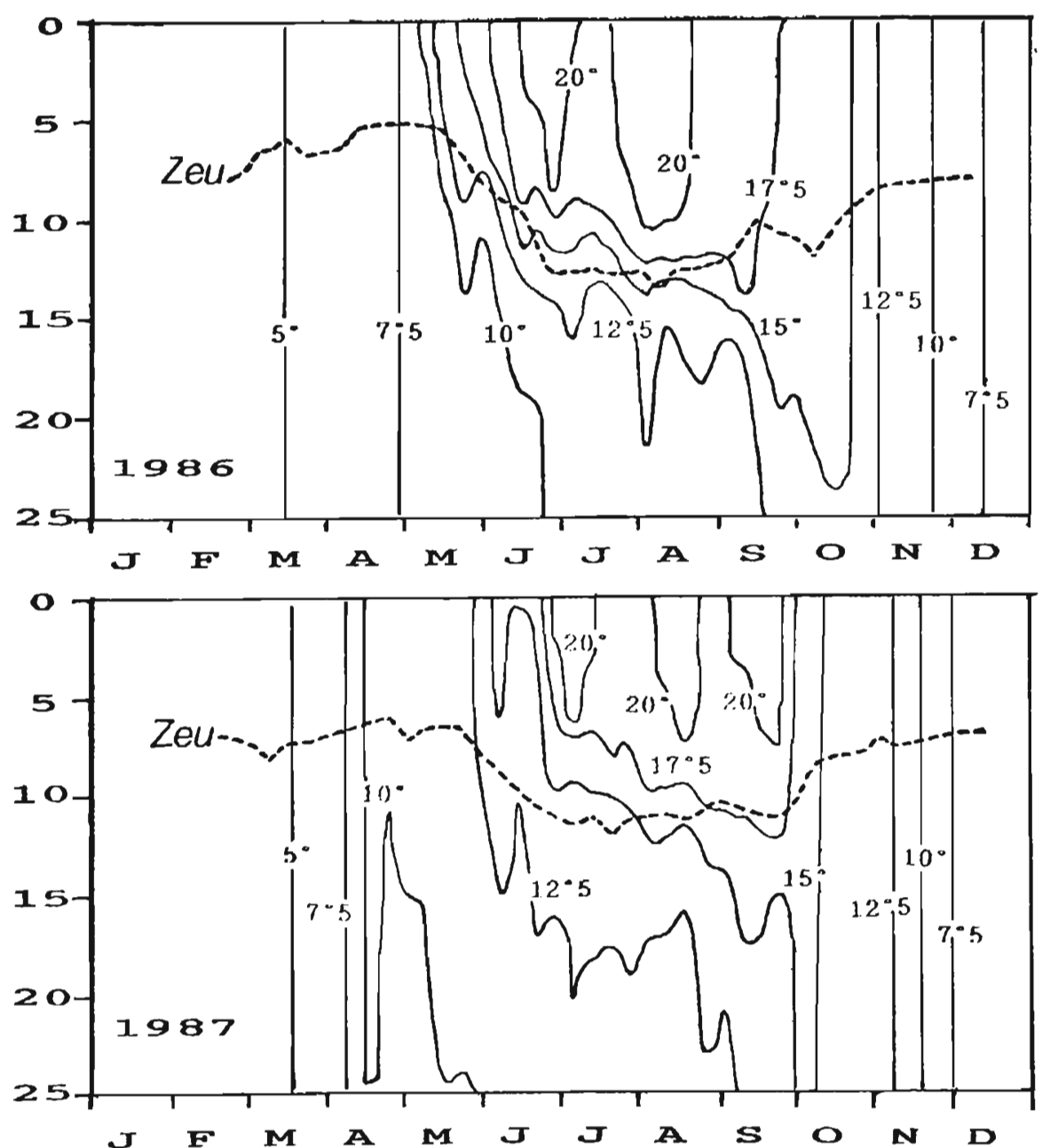

Fig. 1. - Position des isothermes et de la profondeur limite de la couche euphotique $\left(Z_{\text {eu }}=1 \%\right.$ du rayonnement visible en surface) en 1986 et 1987.

Fig. 1. - Temperature isopleths and euphotic depth ( $Z_{\text {eu }}$ as defined by the $1 \%$ irradiance level) in 1986 and 1987.

(NOP) et phosphore (Ppart) indiquent une composition élémentaire moyenne du phytoplancton dans les rapports pondéraux CHLa:C:N:P = $1: 40: 3,8$ : 0,43 . Les rapports moyens $C / N=10,5$ et $\mathrm{N} / \mathrm{P}=8,83$ sont proches des va- leurs rapportées par Harris (1986). A partir de ces relations, on peut estimer que le carbone et l'azote du phytoplancton représentent en moyenne respectivement $39 \%$ et $42 \%$ du COP et du NOP sestonique. 


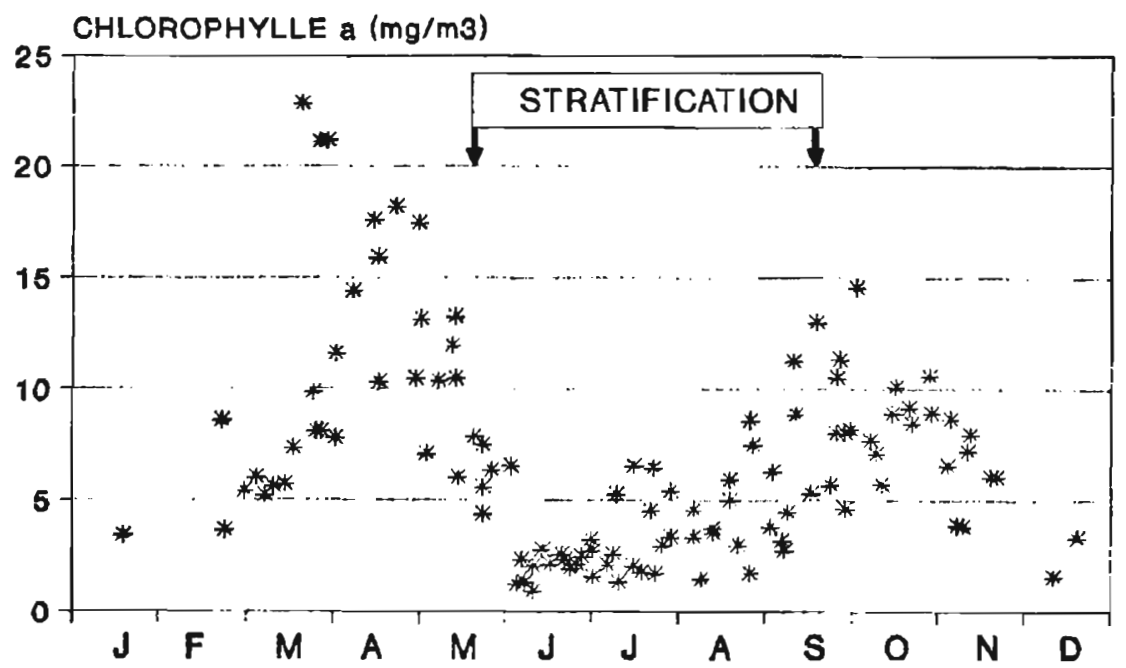

Fig. 2. - Evolution des concentrations moyennes de chlorophylle-a dans la zone euphotique au cours de l'année (les concentrations mesurées de mai 1983 à novembre 1987 sont reportées indistinctement sur le même cycle annuel).

Fig. 2. - Annual cycle of the mean chlorophyll-a concentration within the euphotic zone (the values recorded from May 1983 to November 1987 are plotted on the same annual time series).

\section{Densité et biomasse du bactérioplancton}

Au cours de l'année, les densités bactériennes moyennes sont plus élevées dans la couche euphotique ( $\mathrm{Nze}=$ $3,88 \pm 0,33.10^{9}$ cellules..$\left.^{-1}\right)$ que dans la zone aphotique du lac ( $\mathrm{Nza}=$ $2,5.10^{9}$ cellules $^{-1}{ }^{-1}$ ). Les plus faibles densités s'observent en juin (Nze = $2,5.10^{9}$ cellules. $^{-1} ; \mathrm{Nza}=2,2.10^{9}$ cellules. $I^{-1}$ ); les plus fortes correspondent aux maxima de biomasse de phytoplancton au printemps $(4,5$ à

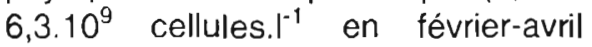
1988 ) et en fin de période de stratification (Nze $=5,9.10^{9}$ cellules. $^{-1}$ en

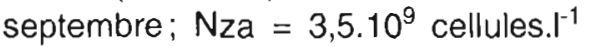
en octobre). Le peuplement bactérien est uniformément réparti dans la co- lonne d'eau en période d'isothermie (fig. 9); les densités sont plus fortes dans la zone euphotique, généralement au voisinage de la thermocline, durant la période de stratification.

Le volume moyen des cellules passe de $0,045 \mu \mathrm{m}^{3}$ en hiver à $0,08 \mu \mathrm{m}^{3}$ en automne; la biomasse bactérienne qui intègre la densité et le biovolume des cellules varie entre 30-35 $\mu \mathrm{g} \mathrm{C.l^{-1 }}$ (novembre-mai) et $100 \mu \mathrm{g} \mathrm{C}^{-\mathrm{I}^{-1}}$ (couche euphotique en septembre). La biomasse moyenne du bactérioplancton durant la période d'étude (avril 1987-septembre 1988) estimée à $51 \pm 3,46 \mu \mathrm{g} \mathrm{C.I^{-1 }}$ représente $15 \%$ de la biomasse moyenne de phytoplancton et $6 \%$ de la quantité moyenne de carbone organique particulaire. 

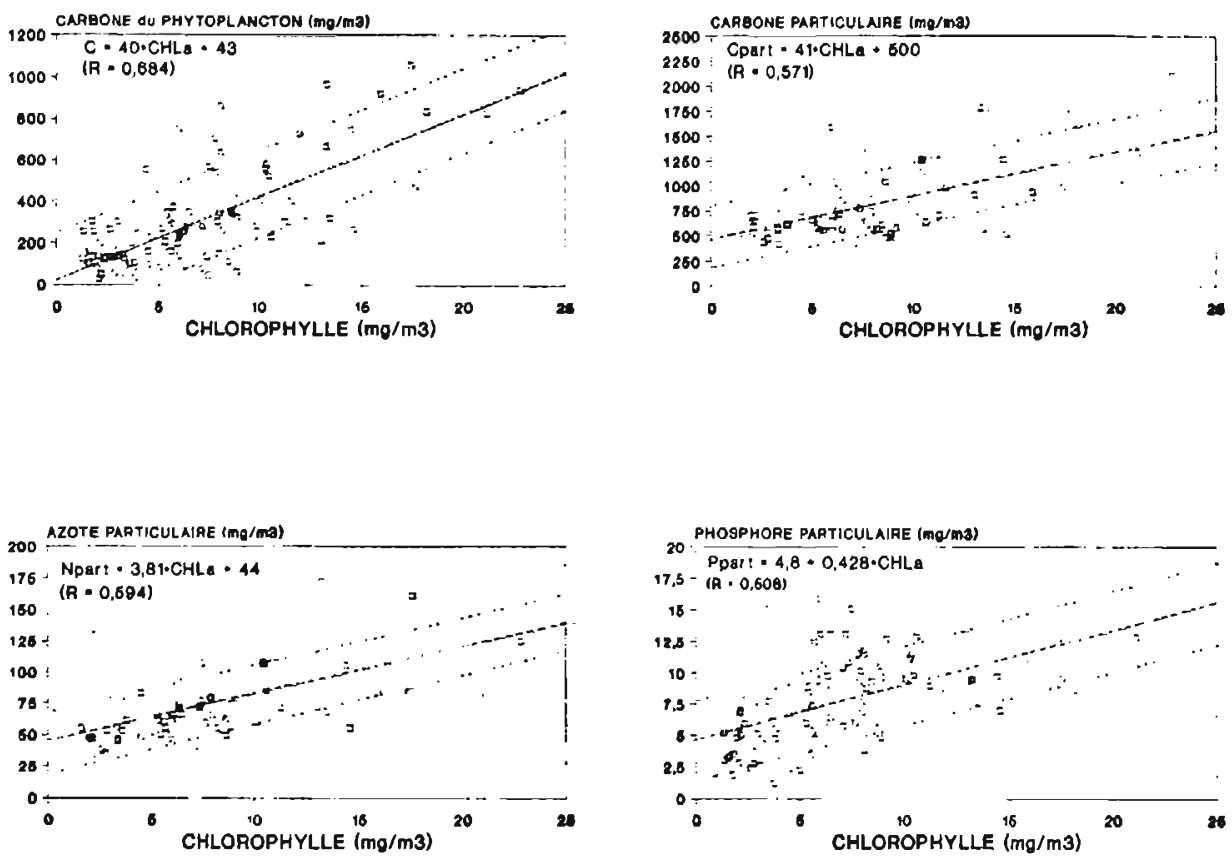

Fig. 3. - Relations entre la concentration moyenne en chlorophylle-a de la couche euphotique, le carbone du phytoplancton estimé à partir du volume des algues et les concentrations de $\mathrm{C}, \mathrm{N}$ et $P$ particulaires.

Fig. 3. - Relationships between mean chlorophyll-a concentration within the euphotic zone and the phytoplankton carbon (estimated from algal volumes), the carbon, nitrogen and phosphorus of the particulate material.

\section{Transmission de la lumière}

Le coefficient d'atténuation vertical des rayonnements dans le domaine du visible $\left(\varepsilon_{v}\right)$ est lié à la profondeur limite de visibilité du disque de Secchi $\left(Z_{d s}\right)$ par la relation:

$$
\varepsilon_{v}=1,006 \cdot Z_{d s}^{-0,506}(R=0,845 ; N=47)
$$

ou, puisque $Z_{e u}=4,6 / \varepsilon_{v}$

$$
Z_{\text {eu }}=4,63 * Z_{d s}^{d, 506}
$$

L'équation de régression entre le coefficient d'atténuation verticale de la lumière $\left(\varepsilon_{v}\right)$ et la concentration moyenne en chlorophylle:

$$
\begin{gathered}
\varepsilon_{v}=0,454+0,019 \text { CHLa } \\
(R=0,645 ; N=56)
\end{gathered}
$$

permet d'estimer le coefficient d'atténuation spécifique de la chlorophylle $\left(\varepsilon_{c}\right)$ à $0,02(\mathrm{mg} \mathrm{CHLa})^{-1} \cdot \mathrm{m}^{2}$. La fraction du coefficient d'atténuation verticale de la lumière attribuable au phytoplancton est de $18 \%$ en moyenne: 
elle varie entre $12 \%$ et $51 \%(\bar{X}=$ $24 \%$ ) au printemps et à l'automne, entre $4 \%$ et $21 \%(\bar{X}=9 \%)$ pendant la phase d'eau claire estivale.

Ces relations peuvent être utilisées pour estimer la profondeur de la couche euphotique à partir des concentrations en chlorophylle. Puisque :

$$
\begin{gathered}
\mathrm{Z}_{\mathrm{eu}}=4,605 /\left(\varepsilon_{\mathrm{c}}(\mathrm{CHL})+\varepsilon_{\mathrm{w}}\right) \\
\mathrm{Z}_{\mathrm{eu}}=4,6 \mathrm{O} 5 /\left(\mathrm{O}, \mathrm{O} 2^{*} \mathrm{CHL}+0,454\right)
\end{gathered}
$$

L'importance de la turbidité non algale $\left(\varepsilon_{w}\right)$ limite généralement l'épaisseur de la couche euphotique à moins de 10 mètres dans la retenue de $\mathrm{Pa}$ reloup (fig. 1); compte tenu de la turbulence générée par le vent, cette couche est le plus souvent isotherme et la distribution verticale du phytoplancton y est homogène.

\section{Relations photosynthèse-lumière}

La production photosynthétique instantanée aux différents niveaux de la couche euphotique (Pz $\left.=\mathrm{mg} \mathrm{C} \cdot \mathrm{m}^{-3} \cdot \mathrm{h}^{-1}\right)$ dépend de la biomasse de phytoplancton présente $\left(B_{2}=\mathrm{mg} \mathrm{CHLa} \cdot \mathrm{m}^{-3}\right)$ et du flux de photons transmis $(I z)$ selon une relation de la forme (Talling, 1957; Vollenweider, 1965; Fee, 1973) :

$$
P z=\frac{B z \cdot P}{B \max \cdot \alpha^{B} \cdot \mid z}
$$

avec :

$\mathrm{z}=10^{*} \exp \left(-\varepsilon_{\mathrm{v}} \cdot Z\right)$

(unités: W. $\mathrm{m}^{-2}=4,66 \mu \mathrm{E} \cdot \mathrm{m}^{-2} \cdot \mathrm{s}^{-1}$ )

$\mathrm{P}^{\mathrm{B}} \max =$ taux de photosynthèse par unité de biomasse en éclairement saturant (unités: $\mathrm{mg} \mathrm{C}$. $(\mathrm{mg} \mathrm{CHLa})^{-1} \cdot h^{-1}$ )
$\alpha^{B}=$ taux de photosynthèse par unité de biomasse et par unité de flux de photons en éclairement limitant (unités : mg C.(mg CHLa) $\left.)^{-1} \cdot h^{-1} \cdot W^{-1} \cdot m^{2}\right)$ $P^{B} \max / \alpha^{B}=I_{k}=$ intensité seuil de saturation par la lumière (unités : W. $\mathrm{m}^{-2}$ ou $\mu E \cdot m^{-2} \cdot s^{-1}$ )

Connaissant les valeurs de $\mathrm{P}^{\mathrm{B}} \max$ et de $\alpha^{B}$ (ou de $\mathrm{lk}$ ), ce modèle permet de simuler l'évolution des profils verticaux de photosynthèse en fonction de lo, $\varepsilon_{v}$, et $B_{z}$ et donc de calculer la production de la couche euphotique intégrée sur la journée. De très nombreux travaux visant à définir les valeurs de ces paramètres biologiques (cf. références in Capblancq, 1982 et Capblancq et al. 1988) ont révélé leur très grande variabilité aux échelles saisonnières ou journalières.

L'analyse des relations photosynthèse-lumière sur 58 profils verticaux de production photosynthétique établis dans le lac de Pareloup confirme cette variabilité des paramètres $\sigma^{B}$ et $P^{B} \max$ (fig. 4) et permet de dégager les points suivants :

(1) Les valeurs de $P^{B}$ max et de $\alpha^{B}$ qui caractérisent l'activité photosynthétique du phytoplancton de Pareloup se situent dans la gamme des valeurs correspondant au phytoplancton de lacs de différents statuts trophiques ( $p$. ex Williams, 1978; Gelin \& Rippl, 1978; Fee et al., 1987); elles sont par contre très nettement inférieures aux valeurs publiées pour le phytoplancton marin (Platt \& Jassby, 1976; Harding et al., 1982; Coté \& Platt, 1983; Bannister \& Weideman, 1984). 
(2) Ces deux paramètres varient simultanément selon une équation de regression linéaire $(r=0,938 ; P<0,1 \%)$ :

$$
P^{B} \max =145 \alpha^{B}-0,02
$$

Plusieurs travaux (Platt \& Jassby, 1976; Harding et al., 1982; Coté \& Platt, 1983; Fee et al. 1987) signalent également une covariation analogue entre les valeurs de $\mathrm{P}^{\mathrm{B}}$ max et de $\alpha^{\mathrm{B}}$. La pente des droites de régression linéaire calculées par ces différents auteurs est comprise entre 95 et $180 \mu \mathrm{E} \cdot \mathrm{m}^{-2} \cdot \mathrm{s}^{-1} \quad$ (moyenne $=140 \mu \mathrm{E}$. $\left.\mathrm{m}^{-2} \cdot \mathrm{s}^{-1}\right)$ ce qui traduit la relative constance du paramètre $I_{k}$ (fig. 4).

(3) La capacité photosynthétique optimale $\left(P^{B}\right.$ max) est inversement corrélée à la biomasse de phytoplancton (fig. 5). Cette tendance peut être partiellement attribuée au fait que les faibles biomasses sont généralement composées d'algues de petite taille. $\mathrm{La}$ relation représentée dans la figure 5 n'explique cependant que $36 \%$ de la variation de $\mathrm{P}^{\mathrm{B}} \max$; celleci peut également résulter d'ajustements adaptatifs du phytoplancton aux conditions d'éclairement qui ont régné pendant la période précédant la mesure (Harris 1978). En conséquence, il n'apparait dans le phytoplancton de Pareloup aucune tendance saisonnière nette dans les variations des paramètres caractéristiques de la relation photosynthèse-lumière (fig. 4).

\section{Production brute journalière et annuelle}

Le phytoplancton étant généralement réparti de manière homogène, la pro- duction photosynthétique intégrée sur la profondeur de la couche euphotique peut être calculée par la relation (Talling, 1957; Vollenweider, 1965) :

$$
\begin{gathered}
\Sigma P_{z}=\left(P^{B} \max \cdot B / \varepsilon_{v}\right) \cdot\left(\ln I_{d} / 0,5 I_{k}\right)= \\
\left(P^{B} \max \cdot B / \varepsilon_{v}\right) \cdot\left(2 \alpha^{B} \cdot I_{d} / P^{B} \max \right)
\end{gathered}
$$

En supposant que les valeurs de $P^{B}$ max et $\alpha^{B}$ (déduites de l'analyse des profils verticaux de photosynthèse mesurés sur des périodes d'incubation de 2 heures à cheval sur le midi solaire) ne varient pas au cours de la journée, il est possible d'estimer la production brute journalière de la couche euphotique $(\Sigma \Sigma P)$ à partir de la relation (Talling 1957, 1971):

$\Sigma \Sigma P_{z}=\left(P^{B} \max \cdot B / \varepsilon_{v}\right) \cdot\left[\overline{\ln }\left(I_{d} / 0,5 I_{k}\right)\right] \cdot D_{j}$ $\Sigma \Sigma P_{z}=m g C \cdot m^{-2} \cdot j^{-1}=$ production brute de la colonne d'eau intégrée sur la profondeur $Z_{e u}$ et la durée du jour $D_{j}$ $\left[\ln \left(I_{d} / 0,5 \cdot I_{k}\right)\right]=$ moyenne de la fonction pendant la durée du jour $\left(D_{j}\right)$ en heures

$\mathrm{B}=$ biomasse moyenne de phytoplancton dans la couche de mélange (mg CHLa.m ${ }^{-3}$ )

$\varepsilon_{v}=$ coefficient d'atténuation verticale de la lumière $=\mathrm{m}^{-1}$

L'intensité des PAR en surface $\left(I_{0}\right)$ intervenant par son logarithme et l'intensité seuil de saturation $\left(I_{k}\right)$ étant relativement stable, les valeurs de production brute journalière dépendent surtout de la durée du jour $\left(D_{j}\right)$, de l'épaisseur de la couche euphotique $\left(Z_{e u}=4,6 / \varepsilon_{v}\right)$ et de la capacité photosynthétique $\left(\mathrm{P}^{\mathrm{B}} \max \right)$; ces deux derniers paramètres variant inversement avec la biomasse (B), le cycle annuel de développement de la bio- 

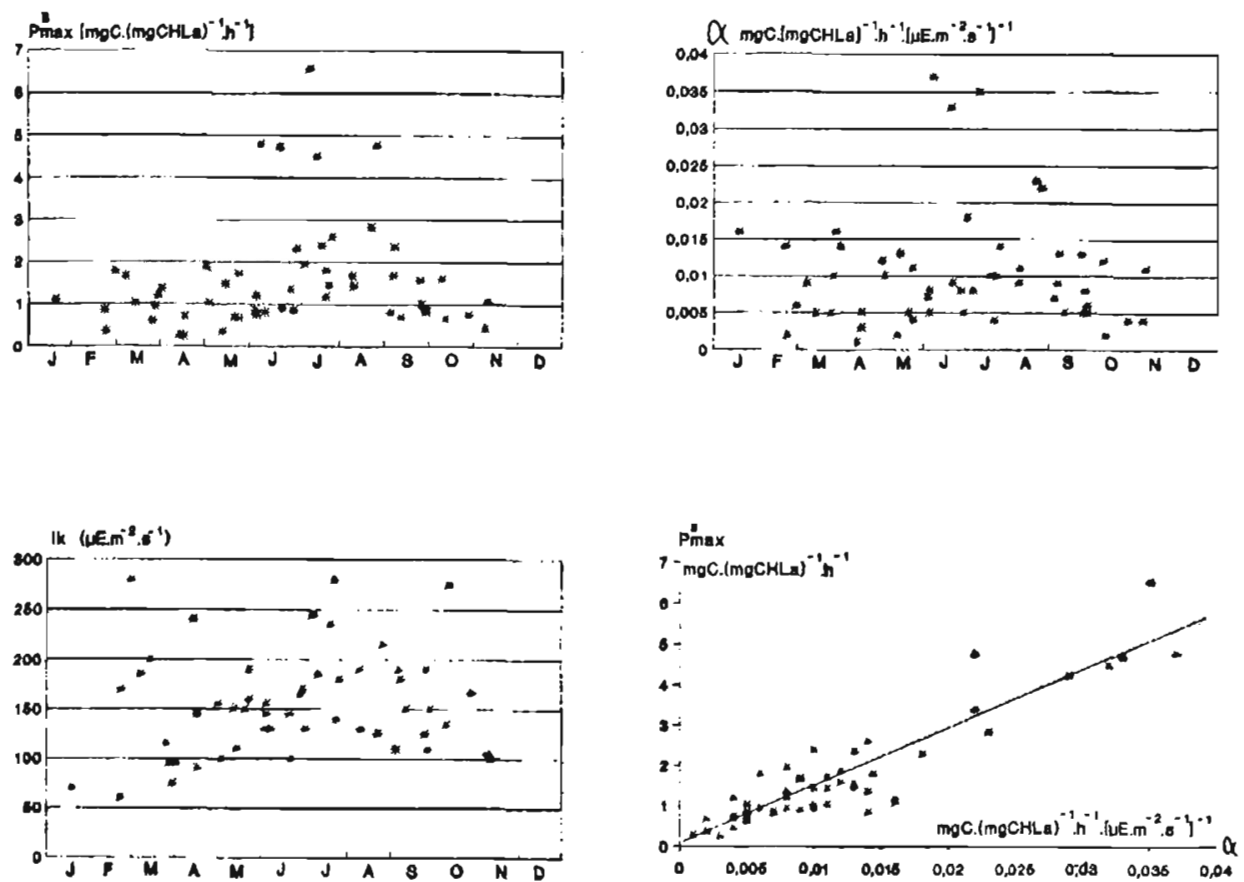

Fig. 4. - Evolution des paramètres $P^{B} \max , \alpha^{B}$ et $I_{k}$ caractéristiques de la courbe photosynthèselumière et relation entre les paramètres $P^{B}$ max et $\alpha^{B}$ (les valeurs mesurées entre mai 1983 et octobre 1987 sont reportées indistinctement sur le même cycle annuel).

Fig. 4. - Seasonal course of the light-saturated photosynthetic activity ( $P^{B}$ max), the initial slope of light-saturation curve $\left.\left({ }^{8}\right)^{B}\right)$, the irradiance level at the onset of light-saturation $\left(I_{k}\right)$ and the relationship between $\mathrm{P}^{\mathrm{B}} \max$ and $\alpha^{\mathrm{B}}$ (the values deduced from photosynthesis-depth profiles; measurements performed from May 1983 to October 1987 are plotted on the same annual time series).

masse (B) de phytoplancton (fig. 2) ne se traduit pas par une évolution parallèle de la production photosynthétique (fig. 6) dont les valeurs se situent le plus souvent entre 150 et $350 \mathrm{mg} \mathrm{C} \cdot \mathrm{m}^{-2} \cdot \mathrm{j}^{-1}$ (moyenne = $245 \mathrm{mg} \mathrm{C} . \mathrm{m}^{-2} \cdot \mathrm{j}^{-1}$ ) entre les mois de mars et de novembre. Les diminutions de $I_{0}$ et de $D_{j}$ expliquent la baisse de la production jounalière en hiver.
A partir des taux de production journalière reportés dans la figure 6 on peut estimer la production primaire brute annuelle de la zone pélagique du lac de Pareloup à $83 \mathrm{~g} \mathrm{C} . \mathrm{m}^{-2} \mathrm{an}^{-1}$ en moyenne. Une part importante de cette production est assurée par le phytoplancton de petite taille, passant au travers de filtres de porosité de $10 \mu \mathrm{m}$ (fig. 7). 


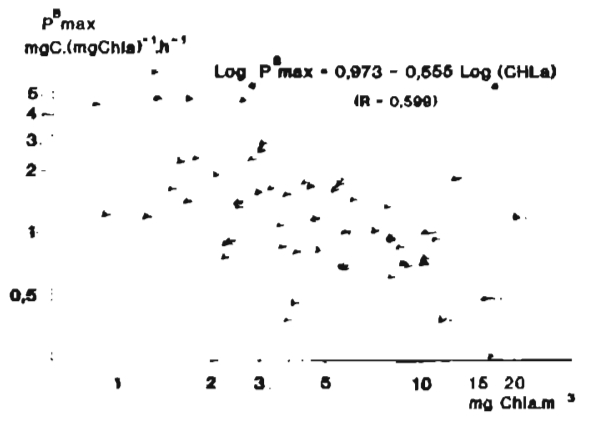

Fig. 5. - Relation entre la capacité photosynthétique en éclairement salurant ( $P^{B}$ max) et la concentration en chlorophylle-a.

Fig. 5. - Relationship between the light-saturated photosynthetic activity $\left(P^{B} \max \right)$ and the chlorophyll-a concentration.

\section{Production brute et production nette}

Pendant deux années consécutives (1986 et 1987) nous avons effectué un enregistrement en continu du rayonnement solaire $\left(I_{0}\right)$ et des mesures hebdomadaires du coefficient d'atténuation de la lumière $\left(\varepsilon_{\mathrm{v}}\right)$ et de la concentration en chlorophylle (B). Ces variables peuvent être utilisées pour calculer l'évolution jour par jour de la production primaire brute à partir des relations entre $P^{B} \max ; \alpha^{B}$ et $B$ établies au paragraphe 3 .

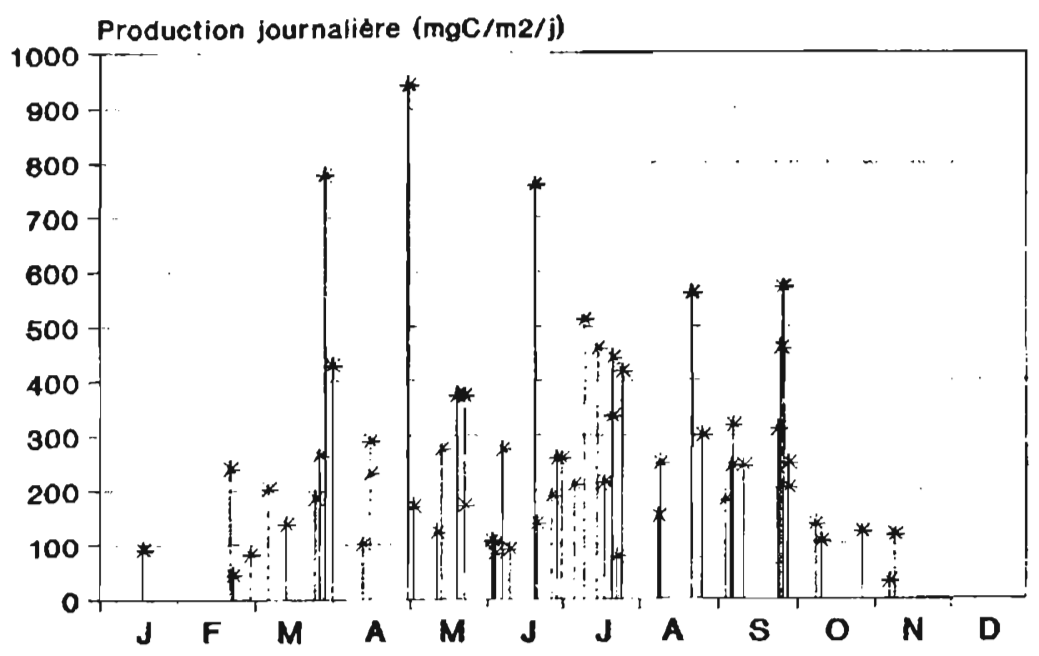

Fig. 6. - Evolution de la production pholosynthéthique journalière brute intégrée sur la profondeur de la couche euphotique. (les taux journaliers estimés entre mai 1983 et octobre 1987 a partir d'incubations d'une durée de 2 heures autour de midi sont reportées indistinctement sur le même cycle annuel).

Fig. 6. - Variations of the daily integral gross photosynthetic production. (Daily rates estimated from 2-hour incubations around noon performed from May 1983 to October 1987 are plotted on the same annual time series). 


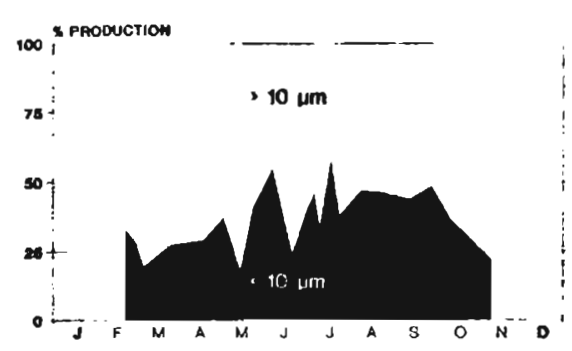

Fig. 7. - Proportions de la production photosynthétique assurées par les algues de tailles inférieures et supérieures à $10 \mu \mathrm{m}$.

Fig. 7. - The percentage contribution of algal size classes lower and higher than $10 \mu \mathrm{m}$ to the total gross production. rates.

Les résultats des simulations faites à l'aide de ces relations sont représentés dans la figure 8 . Ils fournissent une estimation de la production brute entre début mars et fin novembre de $83 \mathrm{~g} \mathrm{C}^{-2}$ en 1986, de $78 \mathrm{~g} \mathrm{C} . \mathrm{m}^{-2}$ en 1987, valeurs très proches de l'estimation moyenne de $83 \mathrm{~g} \mathrm{C} \cdot \mathrm{m}^{-2} \cdot \mathrm{an}^{-1}$ faite à partir des taux de production instantanés mesurés entre 1983 et 1987.

Comparés au taux de variation journalier de la biomasse (exprimée en équivalent carbone à partir de la relation $\mathrm{C}-\mathrm{CHLa}$ ) entre deux relevés successifs (fig. 8), ces taux de production photosynthétique indiquent qu'une très large part du carbone fixé est simultanément éliminé de la colonne d'eau. Ces pertes sont attribuables à la consommation du phytoplancton par les herbivores, à la sédimentation des algues et à la respiration, dans des proportions variables au cours du cycle annuel. A défaut de mesures directes, nous pouvons estimer globalement les pertes par respiration en reprenant les valeurs du rapport $r=P^{B}$ max $/ R^{B}$ trouvées dans la littérature. En désignant par $\Sigma \Sigma R$ les pertes journalières par respiration dans la couche de mélange $Z_{\text {inix }}$ et par $\Sigma \Sigma P$ les gains journaliers par photosynthèse, le bilan de carbone s'écrit:

$\Sigma \Sigma R=r \cdot P^{B} \max \cdot B \cdot Z_{\text {mix }} \cdot 24$

$\Sigma \Sigma P=\left(P^{B} \max \cdot B / \varepsilon_{v}\right) \cdot\left[\ln \left(\left.2\right|_{\delta} / I_{k}\right)\right] \cdot D_{j}$

$\Sigma \Sigma P-\Sigma \Sigma R=$ production journalière nette en $\mathrm{mg} \mathrm{C} . \mathrm{m}^{-2} \cdot \mathrm{j}^{-1}$

On admet généralement que $r=$ 0,1 mais quelques travaux plus récents (Harris 1986, Langdon 1988) suggèrent que ce rapport est plus faible chez les diatomées. En retenant comme valeurs $r_{D}=0,08$ pour le phytoplancton à base de diatomées (période printanière) et $r_{N S}=0,1$ pour le phytoplancton dominé par des algues non siliceuses, on peut estimer les pertes par respiration à $59 \%$ de la production primaire annuelle brute. Selon les valeurs attribuées à $r$, ces pertes varient entre $33 \%\left(r_{D}=0,03\right.$; $\left.r_{N S}=0,07\right)$ et $82 \%\left(r_{D}=0,1 ; r_{N S}=\right.$ $0,15)$.

\section{Production bactérienne}

Au cours de l'année, les taux d'incorporation de thymidine varient beaucoup plus que les densités de bactéries. Ils sont à la fois plus élevés et plus variables dans la zone euphotique (moyenne des estimations mensuelles $=12,1 \pm 2,88$ picomoles.$I^{-1} \cdot h^{-1}$ ) que dans la zone aphotique (5,95 \pm 1,1 picomoles. $\left.I^{-1} \cdot h^{-1}\right)$. 

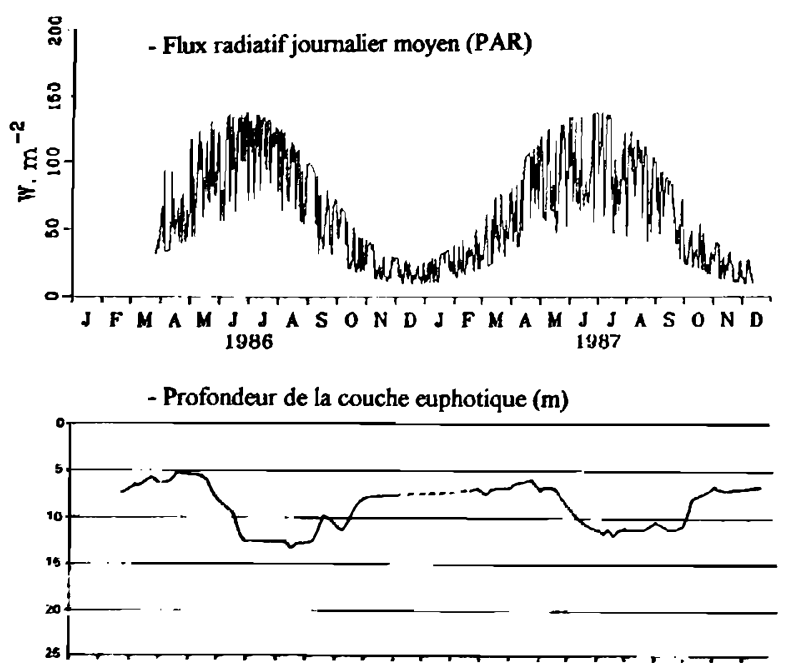

Fig. 8. - Evolution de la production journalière brute et du taux journalier moyen de variation de la biomasse entre deux relevés hebdomadaires au cours des années 1986 et 1987 . Les taux de production journaliers sont calculés à partir du rayonnement incident (a), de la profondeur de la couche euphotique (b) de la concentration moyenne en chlorophylle dans la couche euphotique (c) et des parametres $\mathrm{P}^{\mathrm{B}}$ max et $\mathrm{I}_{\mathrm{k}}$ calculés à partir des figures 4 \& 5 . La zone grisée entre les deux courbes correspond aux pertes par respiration + sédimentation + broutage.

Fig. 8. - Day-to-day variations of integral gross photosynthetic production in 1986 and 1987 as compared with mean daily rates of changes on phytoplankton biomass deduced from weekly measurements of chlorophyll concentrations. Production rates are calculated from surface irradiance (a), euphotic depth (b), mean chlorophyll concentration within the euphotic zone (c) and $\mathrm{P}^{\mathrm{B}}$ max and $\mathrm{I}_{\mathrm{k}}$ values deduced from figs. $4 \& 5$. The discrepancy betwween gross production and actual changes on biomass (shaded area) is attributed to respiration + grazing + sedimentation.

Les taux d'incorporation sont faibles en hiver (moins de 1 picomole. $I^{-1} \cdot h^{-1}$ en janvier). Entre le début du printemps et les mois d'août-septembre, les valeurs s'élèvent de 1 à 30 picomoles. $I^{-1} \cdot h^{-1}$ dans la zone euphotique avec une chute correspondant à la phase de clarification des eaux 

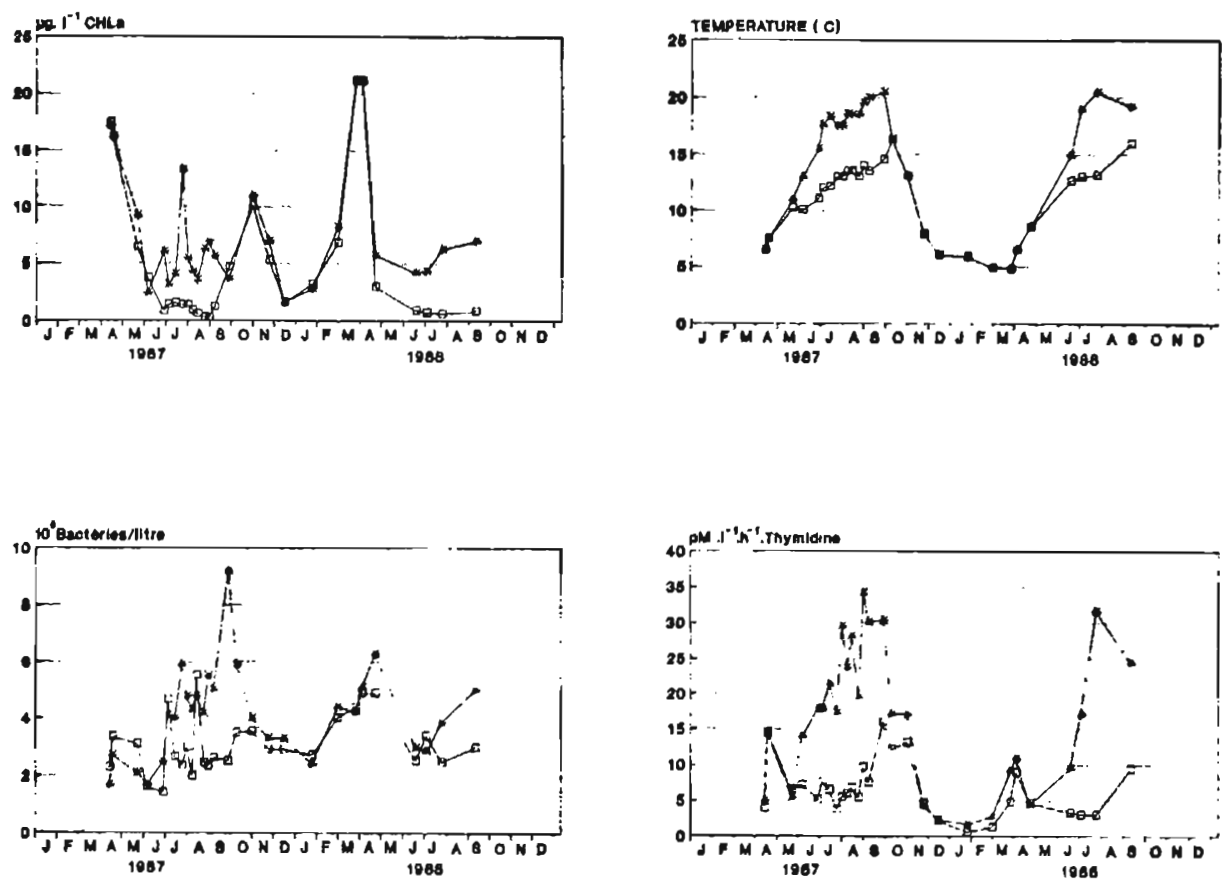

Fig. 9. - Evolution saisonnière des taux d'incorporation de thymidine tritiée, des densités bactériennes, des concentrations en chlorophylle et des températures dans les zones euphotiques (*) et aphotique (0) du lac.

Fig. 9. - Seasonal changes in ${ }^{3} \mathrm{H}$-thymidine incorporation rates, bacterial densities, chlorophyll-a concentrations and temperatures in the euphotic $\left({ }^{*}\right)$ and aphotic $(0)$ zones of the water column of Lake Pareloup from April 1987 to September 1988.
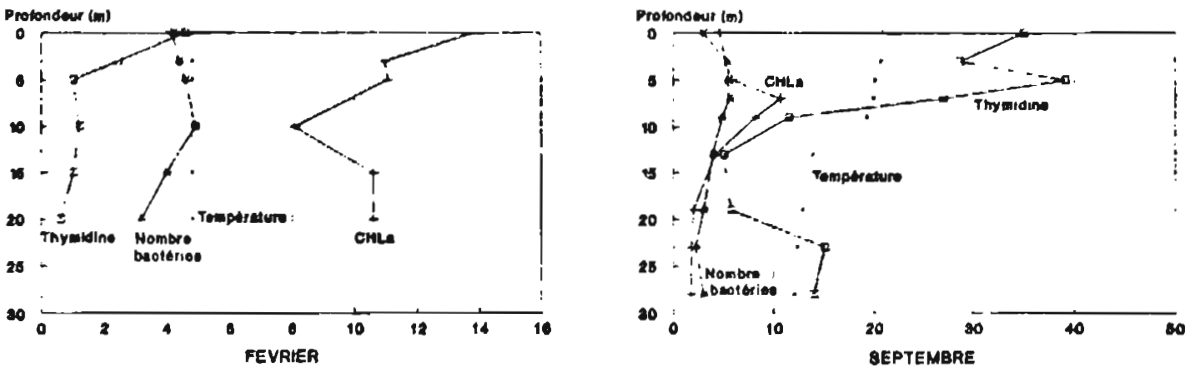

Fig. 10. - Exemples de profils de taux d'incorporation de ${ }^{3} \mathrm{H}$-thymidine $\left(\mathrm{pM} . \mathrm{I}^{-1} \cdot \mathrm{h}^{-1}\right)$, de densités bactériennes $\left(10^{9}\right.$ cells. $\left.\mathrm{I}^{-1}\right)$, de température $\left({ }^{\circ} \mathrm{C}\right)$, de teneurs en chlorophylle a $\left(\mathrm{mg}^{-3} \mathrm{~m}^{-3}\right)$ et en oxygène dissous ( $\mathrm{mg} \mathrm{l}^{-1}$ ) établis dans la partie centrale du lac de Pareloup.

Fig. 10. - Examples of profiles of ${ }^{3} \mathrm{H}$-thymidine incorporation rates $\left(\mathrm{pM} \cdot \mathrm{I}^{-1} \cdot \mathrm{h}^{-1}\right)$, bacterial densities $\left(10^{9}\right.$ cells. $\left.\mathrm{I}^{-1}\right)$, concentrations of chiorophyll a $\left(\mathrm{mg}^{-\mathrm{m}^{-3}}\right)$, dissolved oxygen $\left(\mathrm{mg} . \mathrm{l}^{-1}\right)$ and temperature $\left({ }^{\circ} \mathrm{C}\right)$ obtained for a central water column of Lake Pareloup. 
(fig. 9). La déstratification du lac en automne entraîne une baisse de l'activité attribuable au refroidissement des eaux de surface.

En septembre, les profils verticaux d'activité se caractérisent par deux pics se situant respectivement dans la partie inférieure de l'épilimnion et dans la couche anoxique au voisinage des sédiments (fig. 10). Pendant la période de stratification, les mesures du taux d'incorporation de ${ }^{3} \mathrm{H}$-thymidine dans des eaux de profondeur pratiquement anoxiques ont été réalisées d'une part en maintenant les conditions anaérobies, d'autre part après avoir aéré les échantillons. Dans 5 cas sur 7 , les échantillons aérés et non aérés fournissent des résultats très voisins; en revanche, l'aération de l'eau prélevée en profondeur en septembre a réduit de $50 \%$ le taux d'incorporation de ${ }^{3} \mathrm{H}$-thymidine. Ces résultats suggèrent que le peuplement bactérien de l'hypolimnion est principalement composé de formes anaérobies facultatives mais que des populations strictement anaérobies pourraient se développer dans les zones anoxiques en fin de stratification.

En utilisant un facteur de conversion de $0,5.10^{9}$ bactéries par nanomole de thymidine incorporée et en intégrant les profils d'activité mesurés dans la colonne d'eau, on peut estimer à $114.10^{6}$ cellules. $\mathrm{m}^{-3}$.jour ${ }^{-1}$ la production bactérienne moyenne durant la période considérée. En équivalent carbone, elle correspond à une production moyenne de $1,8 \mathrm{mg} \cdot \mathrm{m}^{-3} \cdot \mathrm{j}^{-1}$ soit $17,7 \mathrm{~g} \cdot \mathrm{m}^{-2}$ par an dans la partie centrale du lac. Les $2 / 3$ de cette production sont réalisés durant les mois d'été et plus de $55 \%$ dans le $1 / 3$ supérieur de la colonne d'eau correspondant à la couche euphotique.

\section{DISCUSSION}

La distribution verticale du phytoplancton dans la couche euphotique du lac de Pareloup est généralement homogène. La production photosynthétique intégrée sur la profondeur de la couche euphotique peut donc être calculée à l'aide du modèle proposé par Talling (1957) en combinant les relations $I=f(Z)$ et $P=f(I)$ qui décrivent respectivement les variations de l'intensité de l'éclairement avec la profondeur et celles de l'activité photosynthétique en fonction de l'intensité de la lumière.

La principale limite à l'utilisation de ce modèle pour convertir les taux de production photosynthétique instantanés en taux journaliers, pour extrapoler les valeurs entre deux mesures hebdomadaires ou pour estimer la production à partir des seules mesures de biomasse et de lumière tient à la variabilité des paramètres qui caractérisent la relation $P=f(I)$. L'analyse des profils d'activité photosynthétique mesurée au midi solaire (Capblancq et al., 1988; ce travail) indique une covariation des paramètres $\alpha^{B}$ et $P^{B} \max$ - donc une relative stabilité de $I_{k}$ - ainsi qu'une relation inverse entre $P^{B} \max$ et la biomasse de phytoplancton. Les valeurs de $P^{B}$ max et de $\alpha^{B}$ tirées de cette analyse 
(figs. 4 et 5) se situent plutôt dans la frange inférieure des valeurs relevées dans la littérature. II est cependant difficile de juger si ces différences résultent des méthodes utilisées pour mesurer les teneurs en chlorophylle et l'activité photosynthétique ou sont liées à la nature du phytoplancton et/ou aux propriétés du milieu.

Les corrélations inverses qui lient les concentrations de chlorophylle aux valeurs de $\alpha^{\mathrm{B}}$, de $\mathrm{P}^{\mathrm{B}}$ max et de $\varepsilon_{\mathrm{v}}$ expliquent en partie l'absence de relation directe apparente entre la production brute journalière et la quantité de phytoplancton contenu dans la zone euphotique. L'augmentation de la transparence et de l'activité photosynthétique qui accompagne les chutes de biomasse se traduit par un maximum de production photosynthétique en été (juillet-août).

Les simulations réalisées à partir de ces relations, de mesures hebdomadaires des concentrations de chlorophylle et de transmission de la lumière et de l'enregistrement en continu de l'éclairement incident (fig. 8), indiquent que les taux journaliers de fixation de carbone excèdent largement les taux de variation de la biomasse. La différence est en grande partie attribuable aux processus de recyclage du carbone au sein de la zone euphotique dont l'importance à été démontrée par Jassby \& Goldman (1974), Pollingher \& Berman (1977) et Tilzer (1984). Les pertes de carbone résultent pour une large part de la respiration. Les modèles de production nette calculés sur la profondeur de la couche de mélange $\left(Z_{\text {mix }}\right)$ sont sensi- bles à de faibles variations des rapports $Z_{\text {eu }} / Z_{\text {mix }}$ et respiration/photosynthèse. Cette sensibilité démontre que la masse de matière organique effectivement produite dans la zone pélagique dépend au moins autant des pertes par respiration que de la capacité photosynthétique des algues et est essentiellement contrôlée par la lumière.

Il est reconnu que la biomasse et l'excrétion extracellulaire des algues planctoniques constituent une source de carbone essentielle pour les bactéries hétérotrophes. A Pareloup, cette relation algues-bactéries est confirmée par l'augmentation de la biomasse et de l'activité bactérienne au printemps et en été lors des maxima de biomasse et de production du phytoplancton. Toutefois, les nombres de bactéries et les taux d'incorporation de thymidine ne présentent pas de relation significative ni avec les taux de production primaire ni avec les concentrations moyennes de chlorophylle dans la colonne d'eau. Cette absence de relation apparente directe a déjà été soulignée dans plusieurs lacs (Brock \& Clyne 1984; Scavia \& Laird 1987); elle montre que la production bactérienne dépend de l'action simultanée d'un ensemble de facteurs incluant non seulement la biomasse et l'excrétion du phytoplancton mais aussi l'autolyse des cellules, les sources allochtones de matière organique, le broutage et le contrôle de l'activité par la température. Dans le lac de Pareloup, l'activité bactérienne est nettement liée à la température : sur l'ensemble de l'année, il y a une bonne corrélation $(P<0,01)$ entre le 
logarithme des taux d'incorporation de thymidine tritiée et la température dans les zones aphotiques $(r=0,54$; $n=28)$ et euphotique $(r=0,86 ; n=$ 28). Les corrélations sont nettement meilleures $(r=0,767$ dans la zone aphotique et 0,962 dans la zone euphotique; $n=23$ ) si on ne tient pas compte de la période printanière où, malgré les températures basses, la croissance bactérienne est stimulée par la production nouvelle de phytoplancton. Cette relation entre température et croissance du bactérioplancton en milieu naturel a été rapportée par plusieurs auteurs (Hobbie \& Cole 1984; Lovell \& Kanopka 1985b; Pomeroy \& Diebel 1986; Scavia \& Laird 1987).

Pour transformer les taux d'incorporation de ${ }^{3} \mathrm{H}$-thymidine en production bactérienne, nous avons utilisé un facteur de conversion de $0,5.10^{9}$ cellules par nanomole de thymidine incorporée dans le précipité insoluble TCA froid. Cette valeur, nettement inférieure à celle que nous avions utilisée initialement (Lavandier 1990) et déterminée expérimentalement dans le lac à partir de cultures en phase de croissance exponentielle (Lavandier \& Faure 1989), est en accord avec les estimations théoriques de ce facteur et conduit, dans une grande variété de milieux d'eau douce, à des estimations de production tout à fait concordantes avec celles basées sur l'incorporation de leucine tritiée (Servais \& Lavandier 1993).

L'incorporation de thymidine tritiée peut être utilisée pour estimer la production bactérienne à la fois en condi- tions aérobies et anaérobies (Pollard \& Moriarty 1984). Cependant, comme l'avait noté Mc Donought et al. (1986), l'oxygénation peut modifier fortement les taux d'assimilation dans les échantillons initialement dépourvus d'oxygène. En outre, l'utilisation d'un facteur de conversion unique pour calculer la production des populations aérobies et anaérobies est douteuse. Dans le lac de Pareloup toutefois, ces imprécisions n'ont que peu d'incidence sur les calculs de production car la période d'anoxie est inférieure à deux mois et le volume d'eau affecté représente moins de $5 \%$ du volume total du lac.

Compte tenu de la morphométrie du lac et des fluctuations de niveau au cours de l'année, ces mesures permettent d'estimer la production nette bactérienne moyenne à $9,3 \mathrm{~g} \mathrm{C} \cdot \mathrm{m}^{-2} \cdot \mathrm{an}^{-1}$. En supposant un rendement de croissance bactérienne de 33\% (Barillier et Garnier 1993), la quantité de carbone nécessaire pour assurer cette production serait de $28,2 \mathrm{~g} \mathrm{C} . \mathrm{m}^{-2}$.an-1, soit $34,3 \%$ de la production photosynthétique brute. Si l'on soustrait de cette dernière la respiration du phytoplancton, cette quantité de carbone assimilée par les bactéries dépasse $50 \%$ de la production primaire nette. Ces proportions sont assez proches des estimations faites dans divers lacs mésotrophes (Güde et al. 1985; Lowel \& Konopka 1985a; Scavia \& Laird 1987; Simon \& Tilzer 1987; Dufour et al. 1989) et eutrophes (PedrosAlio \& Brock 1982; Riemann 1983), compte tenu des différents facteurs de conversion utilisés par ces auteurs. 
La production bactérienne représente environ $7 \%$ de la production primaire brute lors de la poussée printanière de phytoplancton et plus de $70 \%$ en fin d'été. Ce décalage dans le temps entre les productions phytoplanctoniques et bactériennes a été observé dans le lac Tystrupe (Riemann 1983) et dans le lac Michigan (Scavia \& Laird 1987). Ces derniers expliquent ce décalage par une utilisation différée de la production phytoplanctonique par les bactéries. Au printemps, les exsudats des algues constituent un important apport de nutriments que la limitation de l'activité bactérienne par les basses températures ne permet pas d'utiliser complètement : la production bactérienne est alors faible et ne représente que $7 \%$ de la production photosynthétique. La matière organique résiduelle est consommée plus tard, lorsque la température s'élève, conjointement aux exsudats des algues vivantes, aux produits de lyse des algues sénescentes et aux produits d'excrétion des organismes brouteurs. Le maximum de production bactérienne s'observe ainsi en fin d'été, tandis que la production phytoplanctonique décline, le bactérioplancton apparaissant alors comme la voie essentielle du flux d'éléments nutritifs dans la zone pélagique. Ce schéma de l'utilisation du carbone dans le lac et du rôle des bactéries dans le fonctionnement du réseau trophique pélagique devra toutefois être confirmé par des mesures simultanées du carbone organique disponible et de la production bactérienne.

\section{REMERCIEMENTS}

Nous tenons à remercier tout le personnel du laboratoire qui a participé à cette étude et plus particulièrement J.N. Tourenq pour son aide précieuse sur le terrain, D. Dalger qui a réalisé les dosages de $\mathrm{C}$ et de $\mathrm{N}$ et $\mathrm{C}$. Mur, responsable des analyses physico-chimiques.

\section{RÉFÉRENCES}

Bannister T.T. \& A.D. Weidemann, 1984. The maximum quantum yield of phytoplankton photosynthesis in situ. J. Plankton Res. 6 : 275-294.

Barillier A. \& S. Garnier, 1993. Influence of temperature and substrate concentration on bacterial growth yield in Seine River water batch cultures. Appl. envir. Microbiol. 59: 1678-1682.

Bell R.T., 1988. Thymidine incorporation and estimates of bacterioplankton production: Are the conversion factors valid? Ergebn. Limnol. 31: 163-171.

Bjornsen P.K., 1986. Bacterioplankton growth yield in continuous seawater cultures. Mar. Ecol. Prog. Ser. 30: 191-196.

Brock T.H. \& J. Clyne, 1984. Significance of algal excretory products for growth of epilimnic bacteria. Appl. envir. Microbiol. 47 : 731-734.

Calow P., 1977. Conversion efficiencies in heterotrophic organisms. Biol. Rev. 52 : 385-400.

Capblancq J., 1982. Phytoplancton et production primaire. in Pourriot $R$. (ed) "Ecologie du plancton des eaux continentales ", Collection d'Ecologie n' ${ }^{16}$, Masson, Paris : $198 \mathrm{p}$.

Capblancq J., A. Jrad \& J.M. Thébault, 1988. Relation entre la lumière et la photosynthèse du phytoplancton dans un résenoir mésotrophe (Pareloup): 
variations saisonnières des paramètres. Ann. Limnol. 24 : 39-48.

Coté B. \& T. Platt, 1983. Day-to-day variations in the spring-summer photosynthetic parameters of coastal marine phytoplankton. Limnol. Oceanogr., 28 : 320-344.

Dalger D., 1982. Dosage du carbone et de l'azote organiques dans l'eau par chromatographie en phase gazeuse: mise au point et applications de la méthode. These $3^{\text {eme }}$ cycle, UPS Toulouse, 75 pages.

Del Giorgio P.A. \& R.H. Peters, 1993. The influence of DOC on the bacteria-chlorophyll relationships in lakes. Verh. Internat. Verein. Limnol. 25 : 359-362.

Dufour P., S. Stroffek \& M. Colin, 1989. Le bactérioplancton du Léman. Rapport commission internationale pour la protection des eaux du Léman contre la pollution, campagne 1988. C.I.P.E.L. Lausanne $(\mathrm{CH})$ : 71-77.

Fee E.J., 1973. A numerical model for determining integral primary production and its application to lake Michigan. J. Fish. Res. Bd. Can., $30: 1447-1468$.

Fee E.J., R.E. Hecky \& H.A. Welch, 1987. Phytoplankton photosynthesis parameters in central Canadian lakes. J. Plankton Res., 9 : 305-316.

Fuhrman J.A. \& F. Azam, 1980. Bacterioplankton secondary production estimates for coastal waters of British columbia, Antarctica and California. Appl. envir. Microbiol. 39 : 1085-1095.

Fuhrman J.A. \& F. Azam, 1982. Thymidine incorporation as a measure of heterotrophic bacterioplankton production in marine surface waters : evaluation and field results. Mar. Biol. 66 : 109-120.

Gelin C. \& W. Ripl, 1978. Nutrient decrease and response of various phytoplankton fractions following the restauration of lake Trumen, Sweden. Arch. Hydrobiol., $81: 339-367$.

Güde H., B. Haibel \& H. Muller, 1985. Development of bacterial planktonic population in a water column of Lake
Constance (Bodensee-Obersee). Arch. Hydrobiol. 105 : 59-77.

Hagström A., U. Larssen, P. Horstedt \& S. Normark, 1979. Frequency of dividing cells, a new approach to determination of the bacterial growth rates in aquatic environments. Appl. envir. Microbiol. 37 : 805-812.

Harding L.W., B.B. Prezelin, B.M. Sweeney \& J.L. Cox, 1982. Diel oscillation of the photosynthesis-irradiance $(P-1)$ relationship in natural assemblages of phytoplankton. Mar. Biol., 67 : 167-178.

Harris G.P., 1978. Photosynthesis productivity and growth. The physiological ecology of phytoplankton. Ergebn. Limnol. 10: 1-171.

Harris G.P., 1986. Phytoplankton ecology : structure, function and fluctuation. Chapman \& Hall, London : 384 pages.

Hobbie J.E. \& J.J. Cole, 1984. Response of a detrital foodweb to eutrophication. Bull. mar. Sci. 35 : 357-363.

Hobbie J.E., R.J. Daley \& S. Jasper, 1977. Use of nuclepore filters for counting bacleria by fluorescence microscopy. Appl. envir. Microbiol. 44 : 1296-1307.

Jassby A.D. \& C.R. Goldman, 1974. Loss rates from a lake phytoplankton community. Limnol. Oceanogr., 19 : 618-627.

Jordan M.J. \& G.E. Likens, 1980. Measurements of planktonic bacterial production in an oligo-mesotrophic lake. Limnol. Oceanogr. 25 : 719-731.

Langdon C., 1988. On the causes of interspecific differences in the growth-irradiance relationship for phytoplankton. II. A general review. J. Plankton Res., 10: 1291-1312.

Lavandier P., 1990. Dynamics of bacterioplankton in a mesotrophic French reservoir (Pareloup). Hydrobiologia 207 : 79-86.

Lavandier P. \& F. Faure, 1989. Validity of the empirical conversion factors for assessing bacterial production from ${ }^{3} \mathrm{H}$ thymidine incorporation rates. Ann. Limnol. 25 : 93-100. 
Le Cohu R., J. Guitard, N. Comoy \& J. Brabet, 1989. Gonyostomum semen (Raphidophycées), nuisance potentielle des grands réservoirs français, l'exemple du lac de Pareloup. Arch. Hydrobiol. 117 : 225-236.

Le Cohu R., J. Guitard, N. Comoy \& J. Brabet, 1991. Périodicité saisonnière du phytoplancton dans le lac de $\mathrm{Pa}$ reloup. Ann/s. Limnol., 27 : 197-214.

Lee S. \& J.A. Fuhrman, 1987. Relationship between biovolume and biomass of naturally derived marine bacterioplankton. Appl. envir. Microbiol. 53 : 1298-1303.

Lovell C.R. \& A. Konopka, 1985a. Seasonal bacterial production in a dimictic lake as measured by increases in cell number and thymidine incorporation. Appl. envir. Microbiol. 49 : 492-500.

Lovell C.R. \& A. Konopka, 1985b. The effects of temperature on bacterial production in a dimictic eutrophic lake. Microbiol. Ecol. 31: 135-140.

Marker A.F.F., E.A. Nusch \& B. Riemann, 1980. The measurements of photosynthetic pigments in freshwater and standardization of methods: conclusions and considerations. Ergebn. Limnol. $14:$ 91-106.

Mc Donough R.J., R.W. Sanders, K.G. Porter \& D.L. Kirchman, 1986. Depth distribution of bacterial production in a stratified lake with an anoxic hypolimnion. Appl. envir. Microbiol. 52: 9921000.

Pedrós-Alió C. \& T.D. Brock, 1982. Assessing biomass and production of bacteria in eutrophic Lake Mendota, Wisconsin. Appl. envir. Microbiol. 44 : 203-218.

Platt T. \& A.D. Jassby. 1976. The relationship between photosynthesis and light for natural assemblages of coastal marine phytoplankton. J. Phycol., 12: 421-430.

Pollard P.C. \& D.J.W. Moriarty, 1984. Validity of the tritiated thymidine method for estimating bacterial growth rates: measurements of isotope dilution du- ring DNA synthesis. Appl. envir. Microbiol. 48 : 1076-1083.

Pollingher U. \& T. Berman, 1977. Quantitative and qualitative changes in the phytoplankton of lake Kinneret, Israel. 1972-1975. Oikos, 29 : 418-428.

Pomeroy L.R. \& D. Deibel, 1986. Temperature regulation of bacterial activity during the spring bloom in Newfoundland and coastal waters. Science. 233 : 359-361.

Reynolds C.S.1984. The ecology of freshwater phytoplankton. Cambridge University Press, 384 pages.

Riemann B., 1983. Biomass and production of phyto and bacterioplankton in eutrophic Lake Tystrup, Danemark. Freshwat. Biol. 13: 389-398.

Servais P. \& P. Lavandier, 1993. Cohérence des productions bactériennes estimées à partir de l'incorporation de ${ }^{3} \mathrm{H}$-thymidine et de ${ }^{3} \mathrm{H}$-leucine dans les eaux douces naturelles. C.R. Acad. Sci. Paris, Sciences de la Vie; 316 : 642-646.

Scavia D. \& G.A Laird, 1987. Bacterioplankton in Lake Michigan : dynamics, controls, and signifiance to carbon flux. Limnol. Oceanogr. 32 : 1017-1033.

Simon M. \& F. Azam, 1989. Protein content and protein synthesis rates of planktonic bacteria. Mar. Ecol. Prog. Ser. 51: 201-213.

Simon M. \& M. Tilzer, 1987. Bacterial response to seasonal changes in primary production and phytoplankton biomass in lake Constance. J. Plankton Res., $9:$ 535-552.

Talling J.F., 1955. The phytoplankton population as a compound photosynthetic system. New Phytol., 56 : 133-149.

Talling J.F., 1971. The underwater light climate as a controlling factor in the production ecology of freshwater phytoplankton. Mitt. Internat. Verein. Limnol. $19:$ 214-243.

Tilzer M. 1984. Estimation of phytoplankton loss rates from daily photosynthetic rates and observed biomass 
changes in lake Constance. J. Plankton Res., $6: 309-324$.

Valiela I. 1991. Ecology of water columns. in R.S.K. Barnes \& K.H. Mann (eds): "Fundamentals of aquatic ecology", Blackwell, Oxford: 270 pages.

Vollenweider R.A., 1965. Calculation models of photosynthesis - depth curves and some implications regarding day rates estimates in primary production measurements. Mem. Ist. Ital. Idrobiol., (suppl.) 18: 425-457.

Williams N.J., 1978. Annual variation of photosynthetic parameters in lake Tahoe. Verh. Internat. Verein. Limnol., 20 : 419-425. 